\title{
DIVERSIFIKASI PRODUK AREN DALAM RANGKA PENINGKATAN NILAI TAMBAH GULA AREN SEBAGAI PRODUK UNGGULAN DAERAH KABUPATEN LEBONG
}

\section{PALM SUGAR PRODUCT DIVERSIFICATION IN ATTEMPT TO INCREASE ADDED VALUE OF PALM SUGAR AS REGIONAL MAIN PRODUCT OF LEBONG}

\author{
Oleh: \\ Reswita $^{l}$, Satria Putra Utama ${ }^{1}$, Kurnia, Herlina Dewi ${ }^{2}$, dan Zulman Efendi ${ }^{2}$ \\ ${ }^{1}$ Jurusan Sosial Ekonomi Pertanian Fakultas Pertanian Universitas Bengkulu \\ ${ }^{2}$ Jurusan Teknologi Industri Pertanian Fakultas Pertanian Universitas Bengkulu \\ reswita17@yahoo.co.id
}

\begin{abstract}
PPM IbW activity program is done to transfer technology to enhance the knowledge and skills of the society in increased production, increased value added and diversified products of sugar palm processing into a market-oriented product with stable development and small industries with sugar palm based in Lebong Regency. The general objective of this activity is to improve the knowledge and skills of palm sugar farmers in terms of increased production, increased value added and diversified products of sugar palm processing into a market-oriented product so as to increase farmers' income. IbW implementation method is a method of PALS (participatory action learning system) which is based on 3 (three) phases of activity, namely (1) the stage of awareness, (2) the stage of participating / scaffolding, and (3) the stage of institutionalization. The results of this activity in the first year are: 1) Availability of seedlings palm plants, 2) Establishment of joint venture group, 3) improvement of knowledge of craftsmen about industry integration of refined palm sugar from upstream to downstream, 4) improvement of understanding of refined palm sugar craftsmen about health production and hygiene products so as to increase the added value and income, 5) the availability of refined palm sugar maker tools, 6) improvement of the skills of the sugar producers in making refined palm sugar, 7) the availability of machines for packaging, 8) improvement of the knowledge and skills of craftsmen in designing the package, 9 ) Improvement of knowledge and skills in analyzing the results of operations and arranging financial reports, 10) productive economic empowerment for refined sugar palm craftswomen through the creation of market-oriented food products by using palm sugar as a substitute for sugar cane, 11) The formation of product marketing via the internet blogspot. While the activities carried out in the second year are: 1) Technical Assistance of palm seedlings planting, 2) Advanced assistance in palm sugar making, 3) The supply of palm sugar and coffee mixing machine, 4) Training of palm coffee making, 5) Training of Designing package and brand of palm coffee, 6) The assistance in handling business license, 7) Market/Consumer research (organoleptic test), 8) Training and scaffolding of Feasibility Analysis palm coffee business, 9) Products promotion through seminars, exhibitions and competitions. 11) Mentoring supervision and control of safety and health of the housing food products. The results of activities in the Year II (2015) are: 1) Refined Palm Sugar with the
\end{abstract}


label and the new packaging, 2) Palm sugar coffee products, 3) Packaging Design and brand of palm sugar coffee, 4) Business license assistance, 5) Market research/consumer (organoleptic test), 6) Improvement the knowledge and craftsmen skills in analyzing of business feasibility palm sugar coffee, 7) Promote products through exhibitions, 8) Improvement the knowledge of craftsmen by supervision and control of the safety and health of home-cooked foods.

Keywords: Palm sugar, Products diversification, refined palm sugar, palm sugar coffee.

\section{PENDAHULUAN}

Kabupaten Lebong terletak pada posisi $105^{\circ}$ sampai $108^{\circ}$ Bujur Timur dan $02^{\circ} 65^{\prime}$ sampai $03^{\circ} 60^{\prime}$ Lintang Selatan. Secara adminstratif, Kabupaten Lebong berbatasan langsung dengan Sebelah Utara berbatasan dengan Provinsi Jambi, Sebelah Timur berbatasan dengan Provinsi Sumatera Selatan, Sebelah Selatan berbatasan dengan Kabupaten Rejang Lebong dan Bengkulu Utara, dan Sebelah Barat berbatasan dengan Kabupaten Bengkulu Utara.

Luas wilayah Kabupaten Lebong \pm 272.924 Ha terdiri dari 13 kecamatan yang meliputi 100 desa dan 11 kelurahan. Wilayah Kabupaten Lebong didominasi oleh kawasan hutan lindung dan hutan konservasi mencapai 69,90\% dari luas wilayah Kabupaten Lebong. Luas masing-masing kecamatan tersebut adalah sebagai berikut Kecamatan Rimbo Pengadang seluas 12.932 Ha, Topos 34.627 Ha, Lebong Selatan 23.494 Ha, Bingin Kuning 10.815 Ha, Lebong sakti 11.068 Ha, Lebong Tengah 9.196 Ha, Uram Jaya 6.420 Ha, Amen 3.926 Ha, Lebong Utara 5.474 Ha, Pinang Belapis 63.095 Ha, Pelabai 6.178 Ha dan Lebong Atas 5.699 Ha, sedangkan Padang Bano belum ada luas wilayahnya secara pasti karena masa dalam permasalahan dengan kabupaten lain.

Salah satu potensi Kabupaten Lebong yang belum termanfaatkan dan belum dikembangkan secara optimal adalah tanaman aren. Sudah sejak lama daerah Kabupaten Lebong terkenal dengan produksi gula arennya. Berdasarkan data statistik Lebong, luas tanam aren adalah $261 \mathrm{Ha}$, kerapatan tanaman 5-40 batang, tanaman yang menghasilkan 125 Ha dengan total produksi 261 ton. Produksi rata-rata per bulan 1,6 ton, dan produktifitas 850 $\mathrm{kg} / \mathrm{Ha}$. Dari segi kualitas, produk gula aren yang dihasilkan di Kabupaten Lebong lebih bagus dibandingkan dengan daerah penghasil gula aren lainnya yang ada di Provinsi Bengkulu. Akan tetapi dari segi luas perkebunan, pengolahan hasil, peningkatan nilai tambah serta system pemasaran, usaha gula aren di Kabupaten Lebong masih jauh tertinggal. Hal ini dikarenakan keterbatasan pada sumberdaya manusia, infra struktur dan teknologi dan rendahnya pertumbuhan investasi yang dimiliki.

Di Kabupaten Lebong, daerah penghasil gula aren adalah Desa Danau Liang Kecamatan Lebong Tengah dengan jumlah pengrajin lebih kurang 100 orang, Desa Taba Baru Kecamatan Lebong Atas dengan jumlah pengrajin lebih kurang 20 orang, Desa Tes Kacamatan Lebong Selatan dengan jumlah pengrajin lebih kurang 20 orang. Mulai tahun 2013 PemKab Lebong memprioritaskan pengembangan potensi aren yang ada di Kabupaten Lebong dengan memperluas perkebunan aren sebagai salah satu upaya untuk meningkatkan 
produksi dan pengembangan usaha pengolahan aren dalam skala besar yang ditargetkan akan dikembangkan menjadi produk unggulan daerah Kabupaten Lebong. Usaha gula aren merupakan usaha yang sudah cukup lama diusahakan oleh masyarakat di Kabupaten Lebong, namun usaha ini masih bersifat tradisional dan belum berkembang karena masih dijadikan usaha sampingan oleh masyarakat yang ada di Kabupaten Lebong. Wilayah ini belum tersentuh teknologi yang mampu meningkatkan produksi dan pengolahan yang mampu meningkatkan nilai tambah sehingga penghasilan masyarakat gula aren masih cukup rendah. Melalui program Iptek bagi Wilayah dilakukan transfer teknologi tentang teknologi tepat guna dalam pengembangan system agribisnis tanaman aren, mulai dari sub-sistem pengadaan input, sub-sistem budidaya, sub-sistem pengolahan hasil, sub-sistem pemasaran, dan sub-sistem lembaga penunjang agribisnis gula aren di Kabupaten Lebong.

Solusi yang ditawarkan untuk menangani permasalah wilayah sasaran IBW pada tahun I adalah melaksanakan program ipteks bagi wilayah, yakni: 1) pengadaan bibit tanaman aren, 2) pembentukan kelompok usaha bersama, 3) penyuluhan integrasi industry gula semut dari hulu sampai hilir, 4) penyuluhan tentang kesehatan produksi dan higienitas produk sehingga dapat meningkatkan nilai tambah dan pendapatan, 5) pengadaan alat-alat pembuat gula semut, 6) pelatihan pembuatan gula semut, 7) pengadaan mesin untuk kemasan, 8) pelatihan desain merk dan kemasan, 9) pendampingan dalam menganalisis hasil usaha dan penyusunan laporan keuangan, 10) Pemberdayaan ekonomi produktif bagi wanita pengrajin aren melalui pembuatan produk makanan yang berorientasi pasar dengan menggunakan gula semut sebagai pengganti gula tebu, 11) Pendampingan pemasaran produk melalui e-commerce.

Pada tahun II solusi yang ditawarkan untuk menangani permasalah wilayah sasaran IBW 1) Pembuatan gula semut lanjutan dan pembuatan label dan kemasan yang baru, 2) Pelatihan pembuatan kopi aren, 3) Pelatihan Desain Kemasan dan merk Kopi aren, 4) pendampingan Pengurusan izin usaha, 5) Riset pasar/konsumen (uji organoleptik), 6) Pelatihan dan pendampingan Analisis Kelayakan usaha kopi aren, 7) Promosikan produk melalui pameran.

\section{METODE PENGABDIAN}

Metode pelaksanaan kegiatan yang diterapkan dalam upaya untuk mencapai tujuan program adalah metode pemberdayaan masyarakat yang dikenal dengan nama metode PALS (Participatory Action and Learning System) yang dikembangkan oleh Linda Mayouk pada tahun 2000 (Chambers, 2007). Metode PALS ini merupakan salah satu metode yang masuk dalam lingkup metode PLA (Participatory Learning Action) yang merupakan hasil perubahan dari metode RRA (Rapid Rural Appraisal). Beberapa prinsip dasar dari metode PALS ini adalah; 1) menempatkan masyarakat di desa sasaran sebagai objek dan sekaligus 
sebagai subjek kegiatan; 2) pelaksanaan program menggunakan berbagai pendekatan; 3) pelaksanaan program berfokus pada kebutuhan atau kepentingan masyarakat; 4) programprogram memiliki sifat pemecahan masalah, pemberdayaan masyarakat dan pengembangan wilayah; 5) pelaksanaan program bersifat sistemik; dan 6) pelaksanaan program bersifat mencerdaskan dan meransang aktivitas masyarakat.

Dalam program IbW ini, masyarakat dilibatkan mulai dari proses perencanaan, proses pelaksanaan hingga proses monitoring dan evaluasi kegiatan. Dalam tahap perencanaan, tim pelaksana program IbW mengajak perwakilan masyarakat di tiga desa sasaran untuk ikut merencanakan kegiatan yang akan dilaksanakan di masing-masing desa. Pada tahap ini tim pelaksana sibermas menggali informasi dari masyarakat tentang hal-hal yang diperlukan dan diinginkan oleh masyarakat dan tentang potensi-potensi yang ada di desa yang dapat dipakai sebagai modal untuk memenuhi keperluan dan keinginan masyarakat. Informasi tentang halhal yang diperlukan dan potensi-potensi yang dimiliki oleh masyarakat ini kemudian dipakai dasar oleh tim pelaksana program IBW untuk merencanakan bentukbentuk kegiatan. Dalam tahap pelaksanaan, masyarakat di empat desa secara bersama-sama diajak untuk melaksanakan kegiatan dengan difasilitasi oleh tim pelasana program IBW. Dalam kegiatan yang berbentuk pendidikan dan pelatihan (diklat), masyarakat diposisikan sebagai peserta diklat, sedangkan tutor dan narasumbernya diperankan oleh tim pelaksana IBW dan sejumlah narasumber dari luar tim pelaksana program. Dalam kegiatan yang berbentuk pembinaan dan pendampingan terhadap usaha / industri, masyarakat pemilik dan pengelola usaha / industri diposisikan sebagai pihak yang dibina dan didampingi. Sementara itu pembina atau pendampingnya diperankan oleh tim pelaksana program IbW dan beberapa pakar wirausaha dan ekonomi.

\section{HASIL DAN PEMBAHASAN}

Pelaksanaan kegiatan IbW tahun kedua diawali dengan rapat Tim dan Sosialisasi. Sosialisasi Kegiatan IBW dilaksanakan pada tanggal 06 April 2015. Sosialisasi dilakukan oleh Tim IbW kepada Bapak Bupati Kabupaten Lebong, Bappeda, SKPD, dan Kelompok sasaran. Dalam kegiatan ini disosialisasikan kegiatan-kegiatan IbW yang telah dilakukan tahun pertama (2014), yaitu 1) pengadaan bibit tanaman aren, 2) pembentukan kelompok usaha bersama, 3) penyuluhan integrasi industri gula semut dari hulu sampai hilir, 4) penyuluhan tentang kesehatan produksi dan higienitas produk sehingga dapat meningkatkan nilai tambah dan pendapatan, 5) pengadaan alat-alat pembuat gula semut, 6) pelatihan pembuatan gula semut, 7) pengadaan mesin untuk kemasan, 8) pelatihan desain kemasan, 9) pendampingan dalam menganalisis hasil usaha dan penyusunan laporan keuangan, 10) Pendampingan pemasaran produk melalui e-commerce.

Sedangkan pada tahun II IbW (2015) kegiatan yang telah dilaksanakan adalah, 1) Pendampingan teknis penanaman bibit aren, 2) Pendampingan lanjutan pembuatan gula semut, 3) Pengadaan mesin pencampur kopi aren, 4) Pelatihan pembuatan kopi aren, 5) Pelatihan Desain Kemasan dan merk Kopi aren, 6) pendampingan Pengurusan izin usaha, 
7) Riset pasar/ konsumen (uji organoleptik), 8) Pelatihan dan pendampingan Analisis Kelayakan usaha kopi aren, 9) Promosikan produk melalui seminar, pameran dan lomba, 10) Pendampingan pengawasan dan pengendalian keamanan dan kesehatan makanan hasil rumahan. Hasil kegiatan pada Tahun II adalah: 1) Gula semut dengan label dan kemasan yang baru, 2) Produk kopi gula aren, 3) Desain Kemasan dan merk Kopi aren, 4) pendampingan Pengurusan izin usaha, 5) Riset pasar/ konsumen (uji organoleptik), 6) Peningkatan pengetahuan da keterampilan pengrajin dalam menganalisis Kelayakan usaha kopi aren, 7) Promosikan produk melalui pameran, 8) Peningkatan pengetahuan pengrajin dalam pengawasan dan pengendalian keamanan dan kesehatan makanan hasil rumahan

\section{Pelatihan dan pendampingan lebih lanjut pembuatan gula semut}

Pelatihan gula semut lanjutan dilakukan di desa Danau Liang. Pada tahun kedua IbW (2015) pembuatan gula semut langsung menggunakan air nira yang baru dipanen agar mutu produk gula semut yang dihasilkan terjamin, disamping itu warna gula semut yang dihasilkan lebih cerah dan lebih kering. Hal ini juga senada dengan hasil penelitan Baharuddin 2007 yang menyatakan bahwa kualitas aren yang langsung diolah lebih baik disbanding dari yang mengalami proses penyimpanan dan rendemennya lebih rendah. Selain itu juga dilakukan pembaharuan desain label dan penambahan kemasan gula semut yang baru. Kemasan yamg baru dengan warna yang lebih cerah dan lebih bervariasi tujuannya agar konsumen lebih tertarik untuk membeli produk ketika pertama kali mereka melihat produk dan pembelian mereka berlanjut untuk periode berikutnya. Kemasan yang dibuat juga lebih bervariasi seperi kemasan kotak, kemasan tabung, kemasan alumunium foil, dan kemasan botol plastik.

Kemasan Lama

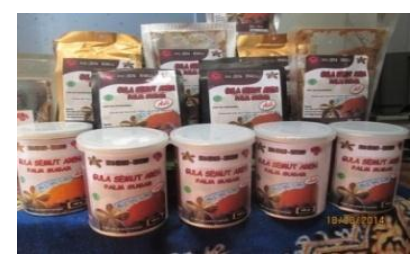

Kemasan Baru

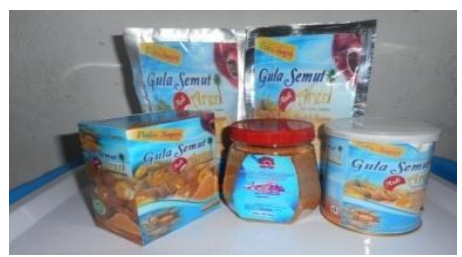

kemasan lama dan baru

\section{Pelatihan pembuatan kopi aren}

Pelatihan pembuatan kopi aren diikuti oleh pengrajin aren, pengrajin kopi, dan masyarakat umum Desa Danau Liang. Tujuannya adalah tumbuh dan berkembangnya kewirausahaan pengolahan kopi gula aren diberbagai lapisan masyarakat. Dalam pelatihan ini ada 6 macam produk yang dihasilkan, yaitu kopi aren original, kopi aren wedang jahe, kopi aren teripang jahe, kopi aren moca, dan kopi aren kimer. 

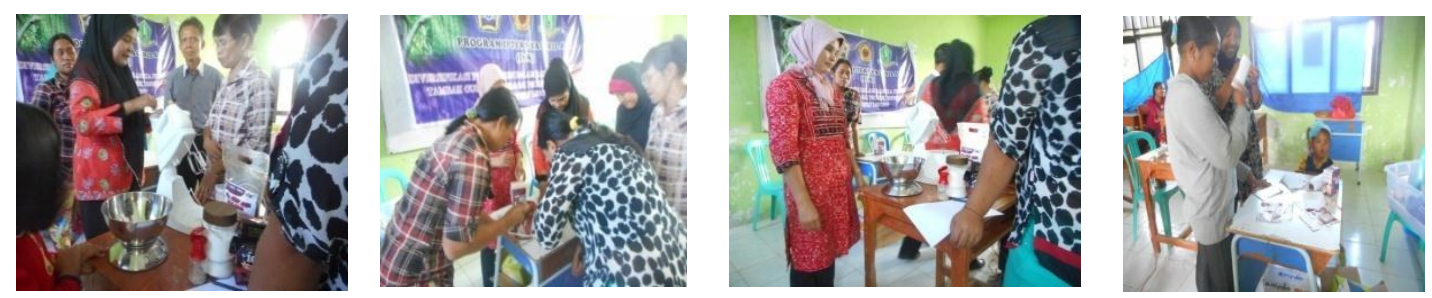

Gambar 2. Pelatihan pembuatan kopi aren

\section{Uji Organoleptik produk kopi gula aren}

Organoleptik merupakan pengujian terhadap bahan makanan berdasarkan kesukaan dan kemauan untuk mempergunakan suatu produk. Uji Organoleptik atau uji indera atau uji sensori sendiri merupakan cara pengujian dengan menggunakan indera manusia sebagai alat utama untuk pengukuran daya penerimaan terhadap produk. Pengujian organoleptik mempunyai peranan penting dalam penerapan mutu. Adapun syarat-syarat yang harus ada dalam uji organoleptik adalah adanya contoh (sampel), adanya panelis, dan pernyataan respon yang jujur. Dalam penilaian bahan pangan sifat yang menentukan diterima atau tidak suatu produk adalah sifat indrawinya. Penilaian indrawi ini ada enam tahap yaitu pertama menerima bahan, mengenali bahan, mengadakan klarifikasi sifat-sifat bahan, mengingat kembali bahan yang telah diamati, dan menguraikan kembali sifat indrawi produk tersebut. Tujuan uji organoleptik adalah untuk pengembangan produk dan perluasan pasar, pengawasan mutu (bahan mentah, produk, dan komoditas), perbaikan produk, membandingkan produk sendiri dengan produk pesaing, evaluasi penggunaan bahan, formulasi, dan peralatan baru. Menurut Sofiah dan Achyar (2008), uji hedonik atau uji kesukaan merupakan suatu cara pengujian untuk mengetahui tanggapan pribadi panelis tentang kesukaan atau ketidaksukaan beserta tingkatannya terhadap suatu produk atau sampel. Tingkat kesukaan ini disebut skala hedonik. Contohnya: amat sangat suka, sangat suka, agak suka, netral, tidak suka, dan sebagainya. Skala hedonik ini dapat direntangkan atau diciutkan.Skala hedonik pun dapat ditransformasikan menjadi skala numeric dengan angka menaik sesuai dengan tingkat kesukaan.Dengan demikian, data yang didapat dapat diolah dengan analisis statistik. Dalam uji organoleptik ini, skala yang digunakan adalah enam (6) skala hedonik yang merupakan skala hedonik seperti amat sangat suka, sangat suka, suka, agak suka, netral dan tidak suka.
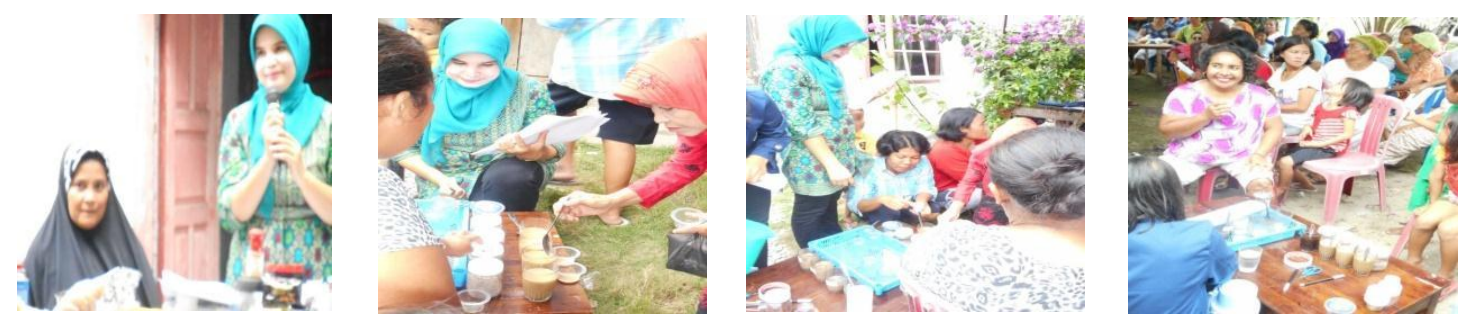

Gambar 3. Uji Organoleptik 


\section{Pelatihan desain kemasan, desain label, dan pembuatan merk kopi aren}

Dalam pelatihan Desain kemasan dan pembuatan label terdapat 3 macam model kemasan,yaitu kemasan Box (kotak), Kemasan tabung, dan kemasan saset. Tujuan pelatihan pengemasan untuk memberikan wawasan dan pengetahuan tentang bahan baku pembuat kemasan, manfaat penggunaan kemasan serta ketrampilan teknis dan desain kemasan produk. Dalam pelatihan pengemasan peserta diberi pemahaman tentang betapa pentingnya arti sebuah kemasan. Kemasan tidak hanya sebagai pembungkus bagi produk, tetapi lebih dari itu merupakan identitas untuk membedakan produk-produk gula semut dan kopi gula aren yang dihasilkan dari perusahaan lain. Dengan identitas khusus produk tertentu akan lebih mudah dikenal konsumen dan pada gilirannya tentu akan memudahkan pada saat pembelian produk tersebut. Dalam pelatihan diberikan pengetahuan tentang unsur-unsur yang harus diperhatikan dalam membuat kemasan, diantaranya ukuran, gambar, warna, tanda Merek, bahan, label, dan bentuk kemasan. Pelatihan pembuatan label dengan menggunakan program photoshop. Pengrajin dikenalkan dengan program photoshop, kemudian dilatih menggunakan program tersebut untuk membuat, mengedit, dan mencetak label. Label produk merupakan salah satu faktor penting label merupakan tanda pengenal sekaligus pembeda dari kompetitor. Melalui label produk dapat disampaikan informasi mengenai brand, kualitas, legalitas, kode produksi, petunjuk, dan lain-lain. Untuk sementara merk produk Kopi gula semut yang dihasilkan yaitu "COLAREN. Merk produk dan Label terlihat seperti gambar yang dilengkapi dengan atribut.
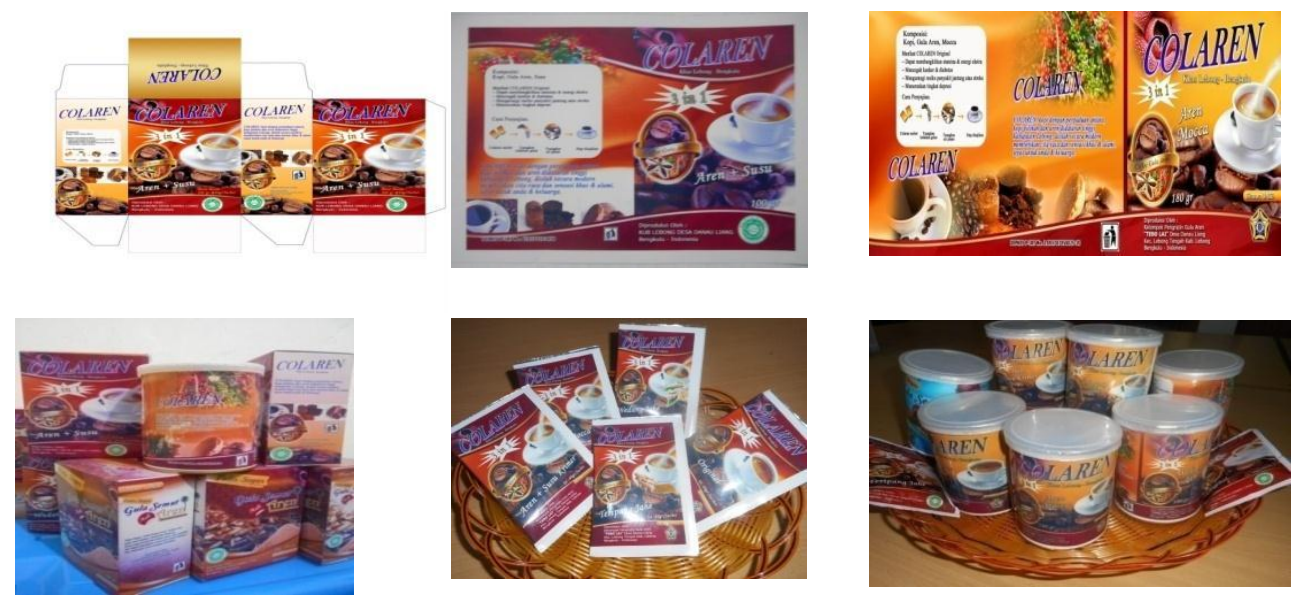

Gambar 4. Pelatihan desain kemasan

\section{Penyuluhan, pengawasan dan pengendalian keamanan kesehatan makanan hasil rumahan, serta pengurusan Nomor PIRT}

Penyuluhan keamanan dan kesehatan produk makanana hasil rumah tangga diberikan kepada pengrajin atau produsen produk makanan desa Danau Liang dan Desa Karang Anyar. 
Dalam kegiatan penyuluhan ini diberi pemahaman kepada para peserta bahwa makanan merupakan kebutuhan dasar bagi manusia yang secara langsung memegang peranan dalam peningkatan kesehatan dan kesejahteraan manusia. Agar hidup sehat dibutuhkan makanan yang bergizi, aman, dan memenuhi syarat mutu kesehatan. Mutu dan keamanan makanan tidak hanya berpengaruh langsung terhadap kesehatan masyarakat, tetapi juga mempunyai pengaruh penting terhadap produktifitas ekonomi dan perkembangan sosial baik individu, masyarakat maupun Negara. Oleh karena itu dalam rangka perlindungan terhadap konsumen maka perlu diupayakan pertemuan para produsen makanan minuman Industri Rumah Tangga untuk meningkatkan pengetahuan dan ketrampilannya dalam memproduksi/ mengolah makanan/minuman agar produk yang dihasilkan memenuhi syarat kesehatan dan memenuhi tuntutan konsumen. Apabila makanan tidak ditangani secara benar atau pengolahannya tidak mengikuti higiene pengolahan makanan yang baik, makanan tersebut dapat menjadi sumber penyakit karena pencemaran mikro organisme dan parasit. Makanan yang menggunakan bahan tambahan makanan yang tepat, baik jenis maupun takarannya tidak menimbulkan gangguan pada kesehatan, sebaliknya penggunaan yang kurang benar dapat menyembunyikan mutu yang kurang dan menutupi kerusakan makanan sehingga dalam keadaan tertentu dapat merugikan kesehatan. Di samping itu cemaran kimia dalam makanan walaupun tidak menimbulkan penyakit akut seperti yang diakibatkan oleh cemaran mikroba dalam jangka panjang dapat menimbulkan gangguan kesehatan. Agar pengelolaan dan penanganan makanan dilakukan dengan benar, setiap orang yang terlibat dalam penanganan makanan harus berperilaku sehat dan memiliki pengetahuan dan ketrampilan yang diperlukan. Setiap pengrajin produk makanan hasil olahan rumah tangga wajib mengetahui dan mematuhi peraturan perundang-undangan di bidang makanan - minuman. Dalam penyuluhan ini juga disosialisasikan tentang Kebijakan Nasional pengaturan IRTP dan peraturan perundang-undangan keamanan pangan, Higiene dan Sanitasi sarana pengolahan, Cara Produksi Pangan yang Baik dan pelabelan yang benar, Pengaturan dan penggunaan Bahan Tambahan Pangan, Berbagai bahaya dalam makanan dan cara menghindarinya, Sertifikasi halal, Ketentuan dan tata cara pemberian ijin usaha industri dan tanda daftar industri.
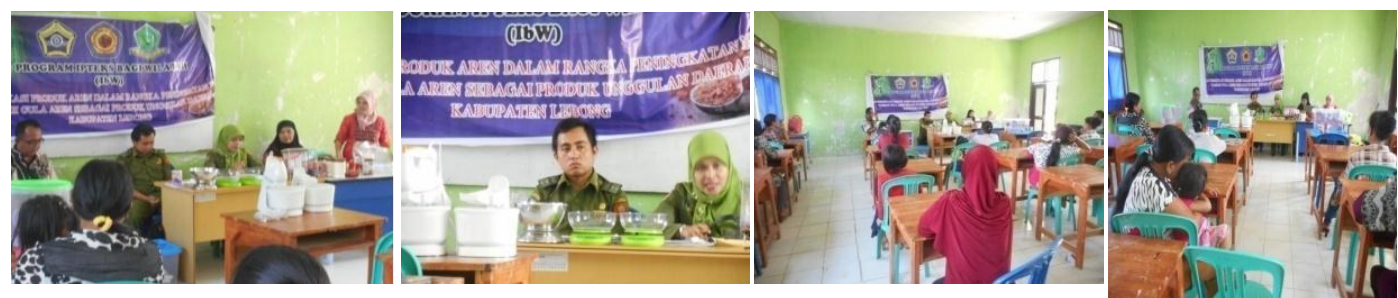

Gambar 5. Penyuluhan, Pengawasan dan Pengendalian keamanan kesehatan makanan hasil rumahan, serta pengurusan No PIRT 


\section{Pelatihan analisis hasil usaha}

Pelatihan ini menghitung harga pokok produksi gula semut dan kopi gula aren.

\begin{tabular}{|c|c|c|c|}
\hline No & Produk & Produk & Produk \\
\hline 1 & $\begin{array}{l}\text { Gula semut kaleng } \\
\text { Gula Semut: } \\
\text { HPP Rp.14.000 }\end{array}$ & $\begin{array}{l}\text { Gula semut kotak } \\
\text { HPP Rp. } 18.000\end{array}$ & $\begin{array}{l}\text { Gula semut botol plastik } \\
\text { HPP Rp.8.000 }\end{array}$ \\
\hline 2 & Collaren Mocca & $\begin{array}{l}\text { Collaren Mocca } \\
\text { HPP Rp. } 25.500\end{array}$ & 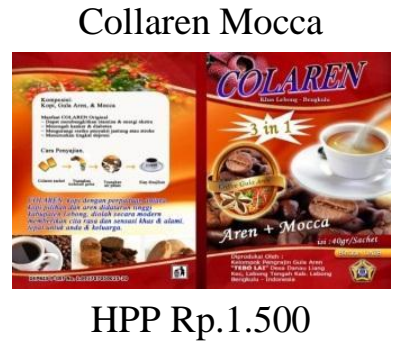 \\
\hline 3 & HPP Rp.15.450 & HPP Rp.25.000 & $\begin{array}{l}\text { Collaren original } \\
\text { HPP Rp.1.500 }\end{array}$ \\
\hline 4 & $\begin{array}{l}\text { Collaren wedang jahe } \\
\text { HPP Rp. } 15.500\end{array}$ & $\begin{array}{l}\text { Collaren wedang jahe } \\
\text { (1) }\end{array}$ & $\begin{array}{c}\text { Collaren wedang jahe } \\
\text { HPP Rp.1.500 }\end{array}$ \\
\hline 5 & $\begin{array}{l}\text { Collaren Krimer } \\
\text { HPP Rp. } 14.500\end{array}$ & HPP Rp. 24.500 & $\begin{array}{l}\text { Collaren Krimer saset } \\
\text { HPP Rp.1.500 }\end{array}$ \\
\hline
\end{tabular}




\section{KESIMPULAN DAN SARAN}

\section{Kesimpulan}

Kegiatan pengabdian pada masyarakat IbW "Diversifikasi Produk Aren Dalam Rangka Peningkatan Nilai Tambah Gula Aren Sebagai Produk Unggulan Daerah Kabupaten Lebong" mendapatkan respon yang positif dari para pengrajin aren dan pemerintah Kabupaten Lebong. Hasil kegiatan pada Tahun II (2015) adalah : 1) Gula semut dengan label dan kemasan yang baru, 2) Produk kopi gula aren, 3) Desain Kemasan dan merk Kopi aren, 4) pendampingan Pengurusan izin usaha, 5) Riset pasar/konsumen (uji organoleptik), 6) Peningkatan pengetahuan da keterampilan pengrajin dalam menganalisis Kelayakan usaha kopi aren, 7) Promosikan produk melalui pameran, 8) Peningkatan pengetahuan pengrajin dalam pengawasan dan pengendalian keamanan dan kesehatan makanan hasil rumahan.

\section{Saran}

Hasil kegiatan IbW ini mendapatkan apresiasi yang baik dari masyarakat dan pemerintah Kabupaten Lebong dan disarankan untuk dilanjutkan.

\section{DAFTAR PUSTAKA}

Anonym, 2011, Lebong dalam Angka, BPS, Kabupaten Lebong.

Anonym, 2011, Laporan Pertanggung Jawaban Bupati Kabupaten Lebong, Kabupaten Lebong, Pemda Kabupaten Lebong, Bapeda.

Anonym, 2012, Rencana Pembangunan Jangka Menengah Daerah (RPJMD) Kabupaten

Lebong, Pemda Kabupaten Lebong, Bapeda.

Anonym, 2012, Pembuatan Gula Aren, http: bi.go.id. diunduh tanggal 20 mei 2013.

Baharruddin, Musrizal Muin, dan Herniaty Bandaso, 2007, Pemanfaatan Nira Aren (Arengan Pinata Merr) Sebagai Bahan Pembuatan Gula Putih Kristal, Jurnal Perennial 3(2) : 40-42, Diunduh tanggal 24 April 2016. 
